\title{
The burden of moderate-to-heavy soil-
} transmitted helminth infections among rural malaysian aborigines: an urgent need for an integrated control programme

\author{
Abdulhamid Ahmed ${ }^{1 *}$, Hesham M Al-Mekhlafi ${ }^{1,2}$, Seow Huey Choy ${ }^{1}$, Init Ithoi ${ }^{1}$, Abdulelah H Al-Adhroey ${ }^{1}$, \\ Awatif M Abdulsalam ${ }^{1}$ and Johari Surin ${ }^{1}$
}

\begin{abstract}
Background: Soil-transmitted helminth (STH) infections, among the most common neglected tropical diseases, continue to be a major threat to the health and socioeconomic wellbeing of infected people especially children in developing countries.

Methods: A cross-sectional study among 254 aboriginal schoolchildren was conducted in order to determine the current prevalence and intensity of infections and to investigate the potential risk factors associated with moderate-to-heavy burden of STH infections among these children.

Results: Overall, $93.7 \%$ of children were found to be infected with one or more STH species. The prevalence of trichuriasis, ascariasis and hookworm infections were $84.6 \%, 47.6 \%$ and $3.9 \%$, respectively. Almost half of the participants had heavy trichuriasis, one-quarter had heavy ascariasis whereas all hookworm infections were light infections. Overall, moderate-to-heavy STH infections accounted for $56.7 \%$ of the total infections. Univariate analysis revealed that those using untreated water supply $(P=0.013)$, living in houses without toilets $(P=0.027)$ and having domestic animals in the houses ( $P=0.044$ ) had significantly higher prevalence of moderate-to-heavy infections than others. Logistic regression analysis confirmed using untreated water for drinking $(P=0.001)$ and the absence of a toilet in the house $(P=0.003)$ as significant risk factors of moderate-to-heavy STH infections among these children.

Conclusion: The high proportion of moderate-to-heavy STH infections further confirms the need for serious attention towards these devastating diseases that has put lives and the future of aboriginal children in jeopardy. Introduction of more poverty alleviation schemes, proper sanitation, provision of clean and safe drinking water, health education, as well as the introduction of periodic school-based deworming programmes are imperative among these communities in order to curtail the transmission and morbidity caused by STH.
\end{abstract}

Keywords: Soil-transmitted helminths, risk factors, aboriginal schoolchildren, Malaysia

\section{Background}

The morbidity caused by soil-transmitted helminths (STH), notably Ascaris lumbricoides, Trichuris trichiura and hookworm, has been a matter of great public health concern throughout the world for decades. Recent estimates suggest that nearly two billion people are infected

\footnotetext{
* Correspondence: hamidmck@yahoo.com

'Department of Parasitology, Faculty of Medicine, University of Malaya,

50603, Kuala Lumpur, Malaysia

Full list of author information is available at the end of the article
}

by these worms worldwide [1,2]. Pre-school and schoolage children in the impoverished communities with low socioeconomic status are more prone to be infected. Therefore, they tend to suffer most from the adverse health consequences of these infections, which include growth retardation, iron deficiency anaemia (IDA), Vitamin A deficiency (VAD), poor cognitive function, school absenteeism and a dismal academic performance [3-7]. However, these consequences are proportional to the worm burden (intensity of infections); infections of

\section{C) Biomed Central}


moderate-to-heavy intensity are associated with greater morbidity whereas infections of light intensity are often asymptomatic $[7,8]$. As the eradication of these infections is not a viable proposition, the WHO aims to curtail the transmission dynamics and to reduce the morbidity caused by the worm burdens on infected individuals [9].

In Malaysia, although great socioeconomic transformation has led to a significant reduction in the prevalence of parasitic infections in urban areas $[10,11]$. STH infections remain highly common among the poor rural and aboriginal populations [12-17]. The continuance of STHs in these communities over the past decades could be due to the enviroment becoming heavily contaminated with the infective stages of these helminths through indiscriminate open defaecation and poor sanitation and therefore, acquiring the infection can hardly be avoided [18]. In such a situation, a better understanding of the risk factors of moderate-to-heavy burden of STH infections would be pertinent to save the vulnerable population from the adverse effects of this infection. Within this context, this study aimed to determine the current prevalence and intensity of STH infections and to investigate the potential risk factors associated with the moderate-to-heavy burdens of infection among the aboriginal schoolchildren in Satak, Pahang, Malaysia.

\section{Methods}

\section{Study area and subjects}

This cross-sectional study was conducted between July and August 2010 in Satak, Raub district, Pahang, located about 200 kilometers northeast of Kuala Lumpur, the national capital of Malaysia. The area consists of aboriginal settlements, located approximately between longitude $101^{\circ} 37^{\prime} 48^{\prime \prime} \mathrm{E}-101^{\circ} 43^{\prime} 47^{\prime \prime} \mathrm{E}$ and latitude $3^{\circ} 59^{\prime} 22^{\prime \prime} \mathrm{N}$ $4^{\circ} 02^{\prime} 03^{\prime \prime} \mathrm{N}$. There are five main communities namely; Pos Satak, Ruai Hulu, Ruai Hilir, Sungai Kelang and Sungai Rensong. Houses are made of wood or bamboo in which environmental sanitation, as well as personal hygiene, was poor. Like other parts of Malaysia, this area has an equatorial rain-forest climate with hot, humid conditions and rainfall throughout the year. The vegetation is of the thick rain forest type and there are few water streams in the area.

Sekolah Kebangsaan Satak (the National School of Satak), a primary school for aboriginal children with a total enrolment of 364 pupils, was selected for this study. However, a total of 289 pupils aged 6-13 years participated voluntarily in the study and were interviewed to fill in the questionnaires. The next day, only 254 of them delivered their stool samples for examination. Therefore, statistical analysis for associations between variables was based on this sample size.

\section{Questionnaire}

The children and their parents were interviewed, in their home settings, to fill in a pre-tested questionnaire for their family background and socioeconomic information. The questions were designed to elicit information on the age, sex, family size, household monthly income, parents' educational and employment status, source of drinking water, presence of toilet facilities, as well as data on medical history and personal hygiene practices.

\section{Parasitology}

The children were given labeled, clean, wide-mouthed and screw-capped containers and were instructed to bring their early morning stool samples the next day. The collected stool samples were transported for examination at the stool processing laboratory in the Department of Parasitology, University of Malaya. The samples were examined by using the Kato-Katz technique as described by Martin and Beaver [19] for the presence of soil-transmitted helminths (A. lumbricoides, T. trichiura and hookworm) eggs. For quality control purposes, duplicate Kato Katz thick smears were prepared for each stool sample. The smears were read twice by two different microscopists. First for hookworm within 30 minutes and second for Ascaris/Trichuris after $40 \mathrm{~min}$ utes or more. An average of the counts were used in this report. To determine the worm burden, egg counts were taken and recorded as eggs per gram of faeces (epg) for each positive sample. Harada-Mori faecal cultivation technique was also used to detect hookworm larva [20]. The results of the Harada Mori technique were consistent with the Kato Katz readings on hookworms. Intensity of infections was graded as heavy, moderate or light according to the criteria proposed by the WHO [21]. Scores for the intensity of infections were given to each STH species (light $=1$, moderate $=2$ and heavy $=3$ ) and infections with species score $\geq 2$ were included in the analysis.

\section{Statistical analysis}

Data analysis was performed using SPSS for Windows software (SPSS version 13). Univariate analysis was used to investigate the association between moderate-toheavy STH infections as the dependent variable and age, sex, parents' educational and employment status, household monthly income, family size, source of drinking water, presence of toilet facilities, have domestic animals at households, playing with the soil and eating soil (geophagy) as the explanatory variables. For the purpose of data analysis, all the factors in the survey were coded in a binary manner. For example, gender (female $=0$, male $=1)$; age $(\geq 10$ years $=0$, Age $<10$ years $=1) ; \mathrm{STH}$ infections (negative-to-light STH infections $=0$, moderate-to-heavy STH infections =1); presence of toilet in 
the house (no $=1$, yes $=0$ ); educational status of parents (no formal education $=1, \geq 6$ years formal education = 0); household monthly income $(<$ RM500 = 1, $\geq$ RM500 =0); source of drinking water (untreated $=1$, treated/piped $=0)$; family size $(>7$ members/large $=1$, $\leq 7$ members $=0$ ); have domestic animals at household (yes $=1$, no $=0$ ) and play barefooted with soil (yes $=1$, no $=0) . P<0.05$ was considered statistically significant. Logistic regression was performed to identify the potential risk factors of moderate-to-heavy STH infections; variables that showed an association with $P \leq 0.20$ were used to develop the multivariate regression model as suggested by Bendel and Afifi [22].

\section{Ethical consideration}

The protocol of this study (Reference Number: 788.74) has been approved by the Medical Ethics Committee of the University of Malaya Medical Centre, Kuala Lumpur, Malaysia. During the visits to the school and the villages, community meetings were held with the headmaster of the school, teachers, heads of the villages, the parents and their school-age children before the commencement of the study in order to give a clear explanation of the objectives of the study. The parents and their children were informed that their participation is voluntary and they can withdraw from the study at any time without assigning any reason whatsoever. All the parents had agreed to have their children participate in the study. Verbal consents were obtained.

\section{Results}

\section{General characteristics of the Subjects}

A total of 254 aboriginal schoolchildren (51.2\% females and $48.8 \%$ males) with a mean age of 9.5 years $(\mathrm{SD}=$ $0.20)$ participated in this study and delivered stool samples for examination. Almost half of the parents had at least 6 years of formal education. Poverty is predominant in the aboriginal communities and about twothirds of their children belonged to low household monthly income families (< RM500; US\$1.00 = RM3.00). The majority of the subjects live in houses without toilets and/or treated water supply. The general demographic and socioeconomic characteristics of the study subjects are shown in Table 1.

\section{Prevalence and distribution of STH infections}

The overall prevalence of STH infections was 93.7\%. The prevalence of trichuriasis, ascariasis and hookworm infections were $84.6 \%, 47.6 \%$ and $3.9 \%$, respectively. Moreover, more than one third of the infected children had mixed infection.

The prevalence of STHs among children aged $<10$ years was almost similar to the prevalence among those aged $\geq 10$ years (91.7\% compared to $95.9 \%$, respectively).
Table 1 General characteristics of the 254 aboriginal schoolchildren participating in the study

\begin{tabular}{ll}
\hline Characteristics & Frequency (\%) \\
\hline Age groups: & \\
$\geq 10$ years & 48.0 \\
$<10$ years & 52.0 \\
Gender: & \\
Males & 48.8 \\
Females & 51.2 \\
Socioeconomic status: & \\
Fathers' education level (at least 6 years) & 51.2 \\
Mothers' education level (at least 6 years) & 46.5 \\
Low household income (< RM500) & 63.0 \\
Working fathers & 89.6 \\
Working mothers & 5.2 \\
Large family size (> 7 members) & 22.4 \\
Piped water supply & 19.3 \\
Presence of toilet (pit or flush) in the house & 48.4 \\
\hline
\end{tabular}

Similar results were reported among the males and females ( $94.4 \%$ compared to $93.1 \%$, respectively).

Moreover, $58.6 \%$ and $53.3 \%$ of the infected children (comprised of $49.6 \%$ and $25.5 \%$ of the examined subjects) had moderate-to-heavy burden of trichuriasis and ascariasis, respectively, whereas, all cases of hookworm infection were of light worm burden. However, the combined moderate-to-heavy STH infections (trichuriasis + ascariasis) accounted for $60.5 \%$ of all the infections (Figure 1).

\section{Risk factors of moderate-to-heavy STH infections}

Univariate analysis results for the association of moderate-to-heavy STH infections with the explanatory variables are illustrated in Table 2 . The results showed that the use of untreated water supply $(\mathrm{OR}=1.90 ; 95 \% \mathrm{CI}=$ $1.14,4.71 ; \mathrm{P}=0.013)$, the absence of toilets $(\mathrm{OR}=1.76$; $95 \% \mathrm{CI}=1.07,2.90 ; \mathrm{P}=0.027)$ and having of domestic animals in the household $(\mathrm{OR}=3.69 ; 95 \% \mathrm{CI}=1.01$, 8.24; $\mathrm{P}=0.044$ ) showed significant associations with the moderate-to-heavy STH infections.

Logistic regression analysis confirmed that consuming untreated water supply as a source of drinking water and for other daily needs $(\mathrm{OR}=2.70 ; 95 \% \mathrm{CI}=1.31$, 5.81; $\mathrm{P}=0.001)$ and the absence of a toilet in the house $(\mathrm{OR}=2.40 ; 95 \% \mathrm{CI}=1.30,4.82 ; \mathrm{P}=0.003)$ were the significant risk factors of moderate-to-heavy burden of STH infections among these children (Table 3).

\section{Discussion}

The present study revealed an alarmingly high prevalence $(93.7 \%)$ of STH infections among aboriginal children in rural Malaysia and this has caused more concern as the prevalence is consistent with previous 


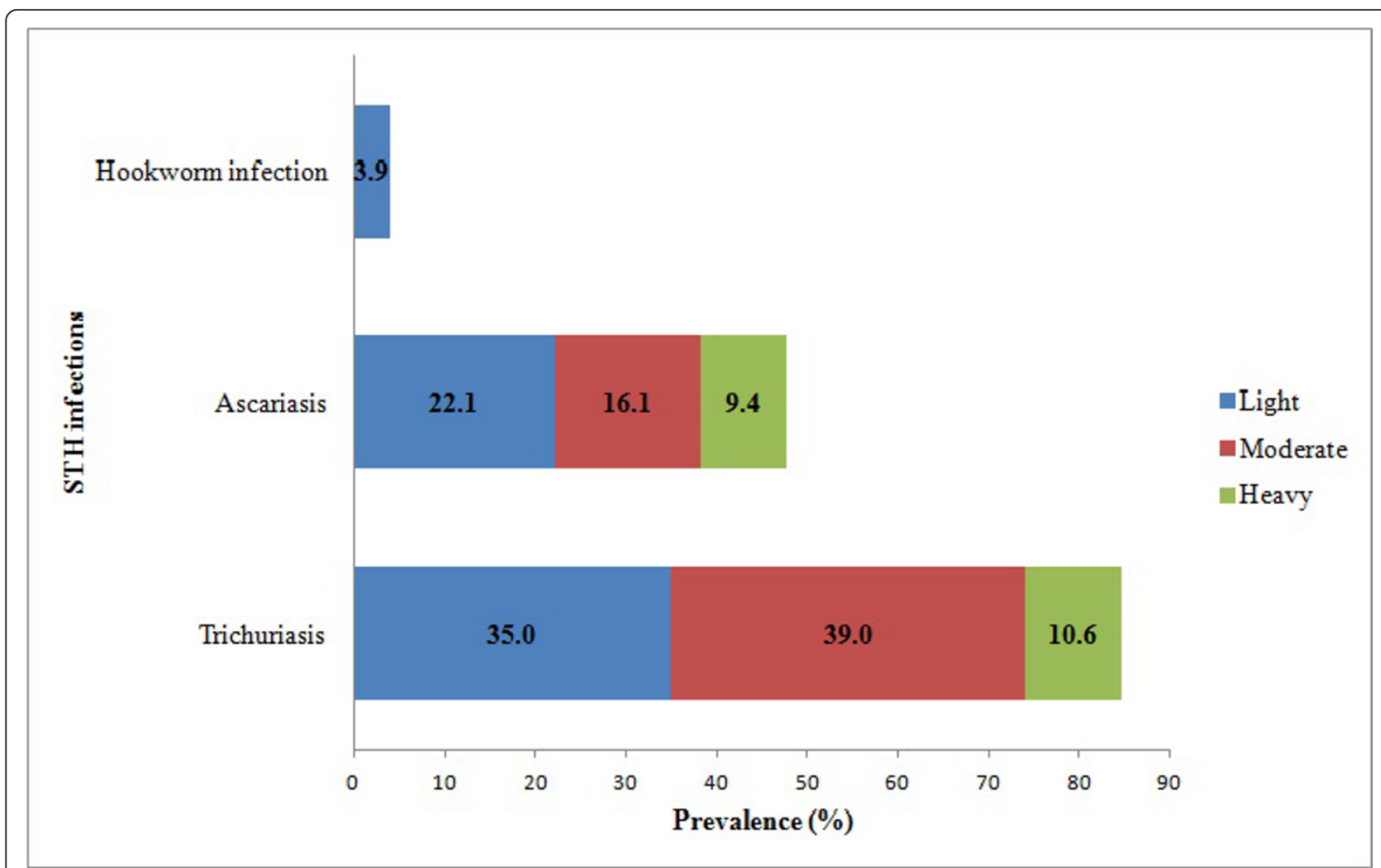

Figure 1 Prevalence and intensity of infections of ascariasis, trichuriasis and hookworm infections among aboriginal schoolchildren in Satak, Pahang $(n=254)$.

studies conducted among aboriginal children in different states of Malaysia over the past decades [12-17]. Despite the significant reduction in the overall prevalence of intestinal parasitic infections in the urban areas $[10,11]$, the trend in rural areas, especially among the underprivileged aboriginal populations, remains largely unchanged with regard to the triad of $A$. lumbricoides, $T$. trichiura and hookworm that continues to afflict these populations at a rate much higher than the threshold recommended by the WHO (20\%) for the implementation of mass deworming of schoolchildren in endemic areas [23]. A national worm control programme was launched in 1974 and rural primary schoolchildren, including aboriginal schoolchildren, received a single dose of pyrantel pamoate once or twice a year (24). However, the programme could not continue because of the fact that pyrantel pamoate was not effective against $T$. trichiura and hookworm, hence, the problem persists.

Evidence from previous reports around the world indicated that ascariasis is more prevalent compared to the other helminth infections [1,2]. However, our study proved trichuriasis as the exceptionally most predominant infection in Malaysia which is consistent with many previous reports $[14,16,24]$. The higher prevalence of $T$. trichiura infection in our survey may represent insusceptibility to the anthelmintic drugs. The adult worm normally lie embedded in the walls of the lumen. Low cure rate of anthelmintic drugs against $T$. trichiura has been reported in Malaysia and abroad $(25,26,27)$. Although there is no convincing proof yet on drug resistance, there is a need for a more detailed investigation of whether drug resistance is emerging in T. trichiura (27). This alarming fact should be given a major consideration in any de-worming programmes in rural Malaysia. As such it may be mandatory to consider a 3-day course of $400 \mathrm{mg}$ Albendazole which has proven to be very effective against heavy trichuriasis among the aboriginal population in Malaysia [18,28]. The low prevalence of hookworm infection reported in this study is also consistent with previous similar studies in Malaysia $[14,17,18]$. This could be due to the non-loamy nature of the soil in most parts of the country, which is not favourable for the development of hookworm larvae.

The results from the present study showed that about two thirds of the subjects infected with T. trichiura and/ or A. lumbricoides had moderate-to-heavy worm burdens, and therefore, they are at risk of suffering the consequences of the infections. This figure is no different from the findings reported previously $[14,16,18]$. 
Table 2 Associations of potential risk factors with moderate-to-heavy STH infections among aboriginal schoolchildren in Satak, Pahang $(n=254)$

\begin{tabular}{|c|c|c|c|}
\hline \multirow[t]{2}{*}{ Variables } & \multicolumn{3}{|c|}{$\begin{array}{l}\text { Moderate-to-heavy STH } \\
\text { infections }\end{array}$} \\
\hline & $\begin{array}{l}\text { Prevalence } \\
\text { (\%) }\end{array}$ & $\begin{array}{l}\text { OR }(95 \% \\
\mathrm{Cl})\end{array}$ & $P$ \\
\hline \multicolumn{4}{|l|}{ Age: } \\
\hline$\geq 10$ years & 62.3 & $\begin{array}{l}1.23(0.98 \\
1.56)\end{array}$ & 0.083 \\
\hline$<10$ years & 51.5 & 1 & \\
\hline \multicolumn{4}{|l|}{ Gender: } \\
\hline Male & 59.7 & $\begin{array}{l}1.27(0.78, \\
2.09)\end{array}$ & 0.348 \\
\hline Female & 53.8 & 1 & \\
\hline \multicolumn{4}{|l|}{ Fathers' education: } \\
\hline No formal education & 59.7 & $\begin{array}{l}1.27(0.77 \\
2.09)\end{array}$ & 0.348 \\
\hline$\geq 6$ years formal education & 53.8 & 1 & \\
\hline \multicolumn{4}{|l|}{ Mothers' education: } \\
\hline No formal education & 59.6 & $\begin{array}{l}1.27(0.78, \\
2.12)\end{array}$ & 0.322 \\
\hline$\geq 6$ years formal education & 53.4 & 1 & \\
\hline \multicolumn{4}{|l|}{ Household income: } \\
\hline$<$ RM500/month (low) & 59.4 & $\begin{array}{l}1.34(0.80 \\
2.24)\end{array}$ & 0.260 \\
\hline$\geq$ RM500/month & 52.1 & 1 & \\
\hline \multicolumn{4}{|l|}{ Family size: } \\
\hline > 7 members (large) & 59.6 & $\begin{array}{l}1.17(0.64 \\
2.13)\end{array}$ & 0.609 \\
\hline$\leq 7$ members & 55.8 & 1 & \\
\hline \multicolumn{4}{|l|}{ Toilet in house: } \\
\hline No & 63.4 & $\begin{array}{l}1.76(1.07 \\
2.90)\end{array}$ & $0.027^{*}$ \\
\hline Yes & 49.6 & 1 & \\
\hline \multicolumn{4}{|l|}{ Source of drinking water: } \\
\hline Untreated (river, rain, well) & 60.5 & $\begin{array}{l}1.90(1.14 \\
4.71)\end{array}$ & $0.013^{*}$ \\
\hline Treated (Piped) & 40.8 & 1 & \\
\hline \multicolumn{4}{|l|}{$\begin{array}{l}\text { Have domestic animals at } \\
\text { household: }\end{array}$} \\
\hline Yes & 58.0 & $\begin{array}{l}3.69(1.01 \\
8.24)\end{array}$ & $0.044^{*}$ \\
\hline No & 27.3 & 1 & \\
\hline \multicolumn{4}{|l|}{ Play barefooted with the soil } \\
\hline Yes & 60.8 & $\begin{array}{l}1.55(0.93 \\
2.58)\end{array}$ & 0.093 \\
\hline No & 50.0 & 1 & \\
\hline
\end{tabular}

OR: odds ratio; $\mathrm{Cl}$ : confidence interval

* Significant association $(P \leq 0.05)$

Considering the strongly-positive relationship between poverty and the pervasive continuance of STH infections, poverty in these communities may play an important role in the persistence of this problem. Heavily infected individuals usually become lethargic and weak and thus unlikely to gain from benefitting fully from
Table 3 Results of multivariate analysis of potential risk factors for moderate-to-heavy STH infections among aboriginal schoolchildren in Satak, Pahang $(n=254)$.

\begin{tabular}{lll}
\hline Variables & \multicolumn{2}{l}{$\begin{array}{l}\text { Moderate-to-heavy STH } \\
\text { infections }\end{array}$} \\
& OR $(\mathbf{9 5 \%} \mathrm{Cl})$ & $\boldsymbol{P}$ \\
\hline Source of drinking water (untreated) & $2.70(1.31,5.81)$ & $0.001^{*}$ \\
Toilet in house (no) & $2.40(1.30,4.82)$ & $0.003^{*}$ \\
Have domestic animals at household (yes) & $2.53(0.68,8.63)$ & 0.152 \\
Age ( $\geq 10$ years) & $1.16(0.57,1.79)$ & 0.584 \\
Play barefooted with the soil (yes) & $1.46(0.74,2.84)$ & 0.273 \\
\hline
\end{tabular}

OR: odds ratio; $\mathrm{Cl}$ : confidence interval

* Significant risk factor $(P \leq 0.05)$

Variables included in the model were age, toilet in house, source of drinking water, have animals at household and playing barefooted with the soil

their domestic and school environments. As infection and its negative impacts are likely to continue to adulthood, their social functioning and wage-earning capacity or productivity in later life may be compromised and thereby the population at risk being trapped in a vicious cycle of poverty and disease which may ultimately affect national development [29]. During our constant visits to the study area and interactions with the children, we observed that many of them always looked tired and weak. School absenteeism rate among them was also high. These could be possibly related to the burden of STH infections among them.

Investigating the possible risk factors associated with moderate-to-heavy STH infections among the participants revealed that using untreated water supply for household needs is a significant risk factor of infection. A similar finding was reported in Ethiopia [30]. Untreated water is always likely to be contaminated with parasites eggs and/or cysts in areas with poor sanitation. Hence, its usage for household activities enhances the likelihood for parasitoses. Moreover, the lack of toilet facilities in the house is another significant risk factor identified by the present study; and this is in agreement with previous reports $[17,18]$.

Contamination of the household surroundings with infected faeces due to the lack of toilets increases the chances of infection and re-infection by STH. The eggs/ larvae of STH can remain viable in the soil for a very long period of time and could easily get picked-up by man or animals. Hence, proper sanitation (which helps break the helminth transmission cycle) is critical to being healthy and considered as a key component in any intestinal parasite control programme [21]. Moreover, our study demonstrated a significant association between moderate-to-heavy STH infections and the presence of domestic animals in the households. Animals such as cats and dogs move about in the contaminated environment and also mix freely with the members of 
their households. Others such as chickens mingle with and feed on the excreta deposited by children around the compound and also move freely within the compound. All these could facilitate the spread of the infections.

Great success has been achieved in many countries in reducing the transmission, prevalence and intensity of STH infections by mass chemotherapy hand-in-hand with improvements in social infrastructures, sanitation and poverty alleviation. For instance, in the Republic of Korea, such programmes were able to reduce the prevalence of STH infections from $84.3 \%$ in 1971 to about $0.02 \%$ in 2004 [31]. A similar story of success was reported in Zanzibar and China [32,33]. Malaysia is witnessing great transformations in terms of socioeconomic and infrastructural developments. Through well planned national control programmes, the country has witnessed great achievements in controlling filariasis and malaria [21]. Similar success can also be achieved by introducing an integrated national helminth control programme, focusing on the vulnerable populations as recommended by the WHO. About 2.5 million rural children attending schools in the country are expected to benefit immensely from this programme when introduced.

\section{Conclusion}

This study reaffirms that STH infections are still prevalent and is a matter of a serious concern in the rural aboriginal communities of Malaysia. There is an urgent need to identify integrated and effective control measures to reduce STH infections significantly in these communities. These measures should focus on reducing poverty, providing proper sanitation, as well as the provision of clean and safe drinking water and proper public enlightenment (health education) regarding good personal hygiene and good sanitary practices. Introduction of school-based de-worming programmes will also help to significantly reduce the prevalence and intensity of the infection in the area.

\section{Acknowledgements}

The authors wish to acknowledge the support and cooperation of the Headmaster, staff and pupils of the National School of Satak in making this survey successful. We also wish to express our appreciation to the parents, and the staff of the District Education Office in Raub, for their kind support and cooperation. This study was supported by the University of Malaya research grants (PS181/2009C \& PS233/2010B).

\section{Author details}

'Department of Parasitology, Faculty of Medicine, University of Malaya, 50603, Kuala Lumpur, Malaysia. ${ }^{2}$ Department of Parasitology, Faculty of Medicine and Health Sciences, Sana'a University, Sana'a, Yemen.

\section{Authors' contributions}

AA was involved in all phases of the study, including study design, data collection, data analysis, interpretation, and write-up of the manuscript; JS, HMA and II designed and supervised the study, and revised the manuscript. HMA was involved in the statistical analysis of data. SHC, AHA and AMA were involved in the collection and laboratory examination of samples. All authors read and approved the final manuscript.

\section{Competing interests}

The authors declare that they have no competing interests.

Received: 25 October 2011 Accepted: 30 December 2011 Published: 30 December 2011

\section{References}

1. De Silva NR, Brooker PJ, Hotez A, Montressor DE, Savioli L: Soil-transmitted helminth infections: Updating the global picture. Trends Parasitol 2003, 19:547-551.

2. Hotez PJ, Brindley PJ, Bethony JM, King CH, Pearce EJ, Jacobson J: Helminth infections: the great neglected tropical diseases. J Clin invest 2008, 118:1311-1321.

3. Stephenson LS, Latham MC, Adams EJ, Kinoti SN, Pertet A: Physical fitness, growth and appetite of Kenyan school boys with hookworm, Trichuris trichiura and Ascaris lumbricoides infections are improved four months after a single dose albendazole. J Nutr 1993, 123:1036-1046.

4. Nokes C, Bundy DAP: Compliance and absenteeism in school children: implications for helminth control. Trans R Soc Trop Med Hyg 1993, 87:148-152.

5. Nor Aini U, Al-Mekhlafi HMS, Azlin M, Shaik A, Sa'iah A, Fatmah MS, Ismail MG, Ahmad Firdaus MS, Aisah MY, Rozlida AR, Norhayati M: Serum iron status in Orang Asli children living in endemic areas of soil transmitted helminths. Asia Pac J Clin Nutr 2007, 16:724-730.

6. Al-Mekhlafi HM, Azlin M, Nor Aini U, Shaik A, Sa'iah A, Fatmah MS, Ismail MG, Ahmad Firdaus MS, Aisah MY, Rozlida AR, Norhayati M: Prevalence and predictors of low serum retinol and hypoalbuminaemia among children in rural Peninsular Malaysia. Trans $R$ Soc Trop Med Hyg 2007, 101:1233-1240.

7. Shang YU, Tang LH, Zhou SS, Chen YD, Yang YC, Lin SX: Stunting and Soil transmitted helminth infections among school age pupils in rural areas of Southern China. Parasit Vectors 2010, 3:97.

8. Nokes C, Grantham-McGregor SM, Sawyer AW, Cooper ES, Robinson BA, Bundy DAP: Moderate-to-heavy infections with Trichuris trichiura affect cognitive function in Jamaican school children. Parasitol 1992, 104:539-547.

9. WHO: Prevention and control of schistosomiasis and soil-transmitted helminthiasis. WHO Technical Series Report; 912 Geneva: World Health Organization; 2002.

10. Mahmood AA, Khairul Anuar A, Sidik K, Salmah I, Suzainur KA, Mohammed NHM, Irwan $\mathrm{H}$ : Comparison of prevalence of intestinal parasitic infections in school children in Kuala Lumpur. J Univ Malaya Med Centre 2002, 2:118-121.

11. Jamaiah I, Rohela M: Prevalence of intestinal parasites among members of the public in Kuala Lumpur, Malaysia. Southeast Asian J Trop Med Public Health 2005, 36:68-71.

12. Dissanaike AS, Vijayamma T, Kan SP, Ong HT: Studies on parasitic infections in Orang Asli (Aborigines) in Peninsular Malaysia. Med J Malay 1977, 32:48-55.

13. Bundy DAP, Kan SP, Rose R: Age-related prevalence, intensity and frequency distribution of gastrointestinal helminth infection in urban school children from Kuala Lumpur, Malaysia. Trans R Soc Trop Med Hyg 1988, 82:289-294.

14. Norhayati M, Zainudin B, Mohammad CG, Oothuman P, Azizi O, Fatmah MS: The prevalence of Trichuris, Ascaris and Hookworm infection in Orang Asli children. Southeast Asian J Trop Med Public Health 1997, 28:161-168.

15. Zulkifli A, Anuar AK, Atiya AS, Yano A: The prevalence of malnutrition and geo-helminth infections among primary schoolchildren in rural Kelantan. Southeast Asian J Trop Med Public Health 2000, 31:339-345.

16. Al-Mekhlafi HMS, Azlin M, Nor Aini U, Shaikh A, Sa'iah A, Fatmah MS, Isma'il MG, Firdaus MSA, Aisah MY, Rozlida AR, Norhayati M: Prevalence and distribution of soil-transmitted helminthiases among Orang Asli 
children living in peripheral Selangor, Malaysia. Southeast Asian J Trop Med Public Health 2006, 37:40-47.

17. Ngui R, Ishak $S$, Chuen CS, Mahmud R, Lim YAL: Prevalence and risk factors of intestinal parasitism in rural and remote West Malaysia. PLoS Negl Trop Dis 2011, 5:e974.

18. Al-Mekhlafi HMS, Surin J, Atiya AS, Ariffin WAW, Mahdy AKM, Abdullah HC: Pattern and predictors of soil-transmitted helminth re-infection among aboriginal school children in rural peninsular Malaysia. Acta Trop 2008, 107:200-204.

19. Martin LK, Beaver PC: Evaluation of Kato thick smears technique for quantitative diagnosis of helminth infections. Am J Trop Med Hyg 1968, 17:382-391.

20. Jozefzoon LM, Oostburg BF: Detection of hookworm and hookworm-like larvae in human fecocultures in Suriname. Am J Trop Med Hyg 1994, 51:501-505.

21. WHO: Malaria, filariasis and other parasitic diseases. Geneva: World Health Organization; 2002.

22. Bendel RB, Afifi AA: Comparison of stopping rules in forward regression. J Am Stat Assoc 1977, 72:46-53.

23. WHO: Preventive chemotherapy in human helminthiasis. Geneva: World Health Organization; 2006.

24. Sagin DD, Mohammed M, Isma'il G, Jok JJ, Lim LH, Pui JNF: Intestinal parasitic infections among five interior communities at upper Rejang river, Sarawak, Malaysia. Southeast Asian J Trop Med Public Health 2002, 33:18-22.

25. Norhayati M, Oothuman P, Azazi O, Fatmah MS: Efficacy of single dose albendazole on the prevalence and intensity of infection of soiltransmitted helminths in Orang Asli children in Malaysia. Southeast Asian J Trop Med Public Health 1997, 28:724.

26. Albonico M, Engels D, Savioli L: Monitoring drug efficacy and early detection of drug resistance in human soil-transmitted nematodes: a pressing public health agenda for helminths control. Int J Parasitol 2004, 34:1205-1210.

27. Penggabean M, Norhayati M, Oothuman P, Fatmah MS: Efficacy of albendazole in the treatment of Trichuris trichuira and Giardia intestinalis infection in rural Malay communities. Med J Malay 1998, 53:408-412.

28. Knopp S, Mohammed AK, Speich B, Hattendorf J, Khamis IS, Khamis AN, Stothard JR, Rollinson D, Marti H, Utzinger J: Albendazole and mebendazole administered alone or in combination with ivermectin against Trichuris trichiura: A Randomized controlled trial. Clin Inf Dis 2010, 51:1420-1428.

29. Bleakley H: Disease and development: evidence from hookworm eradication in the American South. Quart J Econom 2007, 122:73-117.

30. Belyhun Y, Medhin G, Amberbir A, Erko B, Hanlon C, Alem A, Venn A, Britton J, Davey G: Prevalence and risk factors for soil transmitted helminths infection in mothers and their infants in Butajira, Ethiopia: A population based study. BMC Public Health 2010, 10:21.

31. Hong ST, Chai JY, Choi MH, Huh S, Rim HJ, Lee SH: A successful experience of soil-transmitted helminths control in the Republic of Korea. Korean J Parasitol 2006, 44:177-185.

32. Knopp S, Mohammed KA, Rollinson D, Stothard JR, Khamis IS, Utzinger J, Marti H: Changing patterns of soil-transmitted helminthiases in Zanzibar in the context of national helminth control programs. Am J Trop Med Hyg 2009, 81:1071-1078.

33. Zheng $Q$, Chen $Y$, Zhang HB, Chen JX, Zhou XN: The control of hookworm infection in China. Parasit Vectors 2010, 2:44.

doi:10.1186/1756-3305-4-242

Cite this article as: Ahmed et al:: The burden of moderate-to-heavy soiltransmitted helminth infections among rural malaysian aborigines: an urgent need for an integrated control programme. Parasites \& Vectors 2011 4:242.

\section{Submit your next manuscript to BioMed Central and take full advantage of:}

- Convenient online submission

- Thorough peer review

- No space constraints or color figure charges

- Immediate publication on acceptance

- Inclusion in PubMed, CAS, Scopus and Google Scholar

- Research which is freely available for redistribution

Submit your manuscript at www.biomedcentral.com/submit
Biomed Central 